\title{
Management of pediatric obesity
}

\author{
Abbreviations: BMI, body mass index; T2DM, type 2 diabetes \\ mellitus
}

\section{Editorial}

The prevalence of childhood and adolescent obesity is increasing worldwide and constitutes a major public health concern. ${ }^{1}$ Pediatric obesity is defined as body mass index (BMI) equal to or greater than 95th percentiles adjusted for age and sex; the children or adolescents are considered overweight for BMIs between 85 th to 95 th percentiles. ${ }^{2}$ Weight excess in childhood has increased the prevalence of some conditions practically only found in adulthood some years ago, such as impaired glucose tolerance and type 2 diabetes mellitus (T2DM), dyslipidemia, hypertension and liver steatosis. ${ }^{3}$ The early development of these conditions is associated with cardiometabolic mordibity and premature death. ${ }^{4}$ Intervention may prevent those complications or avoid further deterioration of cardiovascular and metabolic status.

The mainstay approach of pediatric obesity is lifestyle modification, which includes dietary changes and stimulation of physical activity, ideally involving also patient's parents, family, friends or even the school. ${ }^{5}$ Dietary and nutritional education must emphasize the reduction or avoidance of calorie-dense, nutrition-poor foods, such as sugar beverages, juices, fast food and moderate to vigorous physical exercise must be promoted, at daily basis with duration of 30 to 60 minutes. ${ }^{6}$ Lifestyle interventions often fail in achieving weight loss and some patients will continue to gain weight and develop metabolic comorbidities. In these circumstances, pharmacotherapy combined with lifestyle measures should be considered only for obese children or adolescents, especially in the presence of cardiovascular risk factors or strong family history of cardiometabolic diseases, such T2DM. Currently, the only FDA-approved drug for obese children (over 12years) is orlistat. However, some other drugs have been studied and used off label to treat pediatric obesity. ${ }^{7}$ Orlistat is a reversible pancreatic lipase inhibitor that limits the absorption of dietary cholesterol in approximately $30 \% .^{5}$ The orlistat largest randomized trial, where 539 obese adolescents were randomized to receive either orlistat $(n=357)$ or placebo $(n=182)$ combined with lifestyle intervention, has shown a significant decrease of BMI after 12 months in the orlistat group $\left(\Delta \mathrm{BMI}-0.55 \mathrm{~kg} / \mathrm{m}^{2}\right.$ vs $+0.31 \mathrm{~kg} / \mathrm{m}^{2}$; $\mathrm{p}=0.001) .{ }^{8}$ Pooling the available data together, $120 \mathrm{mg}$ of orlistat three times daily combined with lifestyle intervention may significantly decrease BMI from 0.5 to $4.09 \mathrm{~kg} / \mathrm{m}^{2}$. The frequent gastrointestinal side effects, occurring in 65 to $100 \%$ of the patients under orlistat, may limit therapy adherence and efficacy. ${ }^{7}$

Metformin stimulates AMP-activated protein kinase, reducing hepatic glucose production, decreasing intestinal glucose absorption and improving the peripheral insulin sensitivity.,10 This drug, wellestablished and FDA-approved for T2DM in children older than 10years of age, has been used off labelin pediatric obesity. ${ }^{9}$ Some randomized trials were conducted in order to clarify metformin role in nondiabetic overweight/obese pediatric patients, and the majority of them suggest metformin beneficial in terms of weight loss and insulin resistance improvement; metformin has also been well-tolerated and safe, with no severe side effects or fatal events described so far., ${ }^{911-13}$
Volume 2 Issue I - 2015

Pedro Marques
Department of Endocrinology, Portuguese Institute of Oncology
of Lisbon, Portugal

Correspondence: Pedro Marques, Department of Endocrinology, Portuguese Institute of Oncology of Lisbon, Rua Professor Lima Basto, 1099-023, Lisbon, Portugal, Tel +35 I 916573936, Fax +351 217229880 , Email pedro.miguel.sousa.marques@gmail.com

Received: January 12, 2015 | Published: January 13, 2015

Thus, metformin is seen as a promising agent to treat obese pediatric patients with impaired glucose tolerance, although its use remains controversial due to the lack of data, especially at long term basis as there are no trials conducted for more than 12 months. ${ }^{11,12}$

The increasing incidence of obesity in the pediatric setting, has led to additional investigation on alternative pharmacological therapies to manage this condition. In the past, sibutramine was approved from FDA to treat pediatric obesity due to its capacity to promote satiety and stimulate the energy expenditure. ${ }^{14}$ It was regarded as an effective drug and extensively used, demonstrating significant decreases of BMI up to $4 \mathrm{~kg} / \mathrm{m}^{2}$ and improvement of metabolic risk factors when compared to placebo groups. ${ }^{15}$ However, issues regarding cardiovascular safety led to sibutramine's withdraw in $2010 .{ }^{16}$ Other experimental drugs have been studied in childhood obesity, such as octreotide, topiramate, growth hormone, leptin but conclusive data or significant trials are not available, therefore those cannot be recommended. ${ }^{5}$

Ultimately, selected cases of severe pediatric obesity may be considered for bariatric surgery. This approach, highly effective to treat adult obesity, has several potential complications in the pediatric setting. Bariatric surgery may be considered only if the children has BMI $>50 \mathrm{~kg} / \mathrm{m}^{2}$ or $\mathrm{BMI}>40 \mathrm{~kg} / \mathrm{m}^{2}$ with comorbidities, if lifestyle modification with or without pharmacological intervention fails and if a pubertal Tanner $4 / 5$ status and final/near-final adult height was already achieved..$^{5,17}$

Summarizing, the increasing incidence of pediatric obesity and its cardiometabolic impact, the disappointing effectiveness of lifestyle intervention and the lack of pharmacological alternatives to treat this condition, justifies the efforts from medical community to find effective (new) drugs and to expand the knowledge on the available drugs to treat this entity. Thus, considering the high relevance of this topic, we hope to have contributors and original research data to expand the scientific knowledge on this matter.

\section{Acknowledgements}

None.

\section{Conflict of interest}

Author declares that there is no conflict of interest. 


\section{References}

1. Ogden CL, Carroll MD, Curtin LR, et al. Prevalence of high body mass index in US children and adolescents, 2007-2008. JAMA. 2010;303(3):242-249.

2. Wang Y, Lobstein T. Worldwide trends in childhood overweight and obesity. Int J Pediatr Obes. 2006;1(1):11-25.

3. Li C, Ford ES, Zhao G, et al. Prevalence of pre-diabetes and its association with clustering of cardiometabolic risk factors and hyperinsulinemia among U. S. adolescents: National health and nutrition examination survey 2005-2006. Diabetes Care. 2009;32(2):342-347.

4. Must A, Jacques PF, Dallal GE, et al. Long-term morbidity and mortality of overweight adolescents. A follow-up of the Harvard Growth Study of 1922 to 1935 . N Engl J Med. 1992;327(19):1350-1355.

5. August GP, Caprio S, Fennoy I, et al. Prevention and treatment of pediatric obesity: an endocrine society clinical practice guideline based on expert opinion. J Clin Endocrinol Metab. 2008;93(12):4567-4599.

6. Pate RR, Davis MG, Robinson TN, et al. Promoting physical activity in children and youth: a leadership role for schools: a scientific statement from the American Heart Association Council on Nutrition, Physical Activity, and Metabolism (Physical Activity Committee) in collaboration with the Councils on Cardiovascular Disease in the Young and Cardiovascular Nursing. Circulation. 2006;114(11):1214-1224.

7. Matson KL, Fallon RM. Treatment of obesity in children and adolescents. J Pediatr Pharmacol Ther. 2012;17(1):45-57.

8. Chanoine JP, Hampl S, Jensen C, et al. Effect of orlistat on weight and body composition in obese adolescents: a randomized controlled trial. JAMA. 2005;293(23):2873-2283.
9. McDonagh MS, Selph S, Ozpinar A, et al. Systematic review of the benefits and risks of metformin in treating obesity in children aged 18 years and younger. JAMA Pediatr. 2014;168(2):178-184.

10. Rojas J, Arraiz N, Aguirre M, et al. AMPK as target for intervention in childhood and Adolescente obesity. J Obes. 2011;2011:252817.

11. Kendall D, Vail A, Amin R, et al. Metformin in obese children and adolescents: the MOCA Trial. J Clin Endocrinol Metab. 2013;98(1):322-329.

12. Yanovski JA, Krakoff J, Salaita CG, et al. Effects of metformin on body weight and body composition in obese insulin-resistant children: a randomized clinical trial. Diabetes. 2011;60(2):477-485.

13. Osborne KL, Sheeder J, Zeitler P. Addition of metformin to a lifestyle modification program in adolescents with insulin resistance. $J$ Pediatr. 2008;152(6):817-822.

14. Ryan DH, Kaiser P, Bray GA. Sibutramine: a novel new agent for obesity treatment. Obes Res. 1995;3(Suppl 4):553S-559S.

15. Berkowitz RI, Fujioka K, Daniels SR, et al. Effects of sibutramine treatment in obese adolescents: a randomized trial. Ann Intern Med. 2006;145(2):81-90.

16. James WP, Caterson ID, Coutinho W, et al. Effect of sibutramine on cardiovascular outcomes in overweight and obese subjects. $N$ Engl J Med. 2010;363(10):905-917.

17. Apovian C, Baker C, Ludwig D, et al. Best practice guidelines in pediatric/adolescent weight loss surgery. Obes Res. 2005;13(2):274-282. 